\title{
Monthly fluctuations in radial growth of individual lobes of the lichen Parmelia conspersa (Erhr. ex Ach.) Ach.
}

\author{
R.A. Armstrong \\ Vision Sciences, Aston University, Birmingham B4 7ET, UK, Tel. +44-121-359-3611, Fax. +44-121-333-4220, \\ Email. R.A.Armstrong@aston.ac.uk
}

(Received January 22, 2008; Accepted May 8, 2008)

\begin{abstract}
The radial growth (RG) of 120 lobes from 35 thalli of the foliose lichen Parmelia conspersa (Ehrh. ex Ach.) Ach. was studied monthly over 22 months in south Gwynedd, Wales, UK. Autocorrelation analysis of each lobe identified three patterns of fluctuation: 1) random fluctuations (58\% of lobes), 2) a cyclic pattern of growth (23\% of lobes), and 3 ) fluctuating growth interrupted by longer periods of very low or zero growth (19\% of lobes). In $80 \%$ of thalli, two or three patterns of fluctuation were present within the same thallus. Growth fluctuations were correlated with climatic variables in $31 \%$ of lobes, most commonly with either total rainfall or number of rain days per month. Lobes correlated with climate were not associated with a particular type of growth fluctuation. RG of a lobe was positively correlated with the degree of bifurcation of the lobe tip. It is hypothesised that lobes of $P$. conspersa exhibit a cyclic pattern of growth due in part to lobe division. The effects of climate, periods of zero growth, and microvariations in the environment of a lobe are superimposed on this cyclic pattern resulting in the random growth of many lobes. Random growth fluctuations may contribute to the maintenance of thallus symmetry in $P$. conspersa.
\end{abstract}

Keywords: Parmelia conspersa, marginal lobes, temporal fluctuations, radial growth, lobe division, thallus symmetry, time series, autocorrelation

\section{Introduction}

The margin of a foliose lichen thallus comprises individual lobes that vary in size and shape (Benedict and Nash, 1990; Hill, 1992), the stage of division of the lobes (Hill, 1984; Armstrong, 1995; Armstrong and Smith, 1999), and the degree to which lobes are physically connected to their neighbours (Armstrong, 2003). In addition, lobes are often crowded together at the margin resulting in lateral competition between neighbours (Hooker, 1980; Benedict, 1990; Armstrong, 2003). However, lobes in mature thalli do not fuse extensively when they come into contact, unlike the earlier more undifferentiated stages where fusion of different parts are common. Hence, individual lobes maintain their individuality and a considerable degree of autonomy (Hale, 1973; Aplin and Hill, 1979; Armstrong 1991, 1993a) resulting in substantial variations in radial growth (RG) from lobe to lobe (Phillips, 1969; Lawrey and Hale, 1977; Benedict and Nash, 1990; Armstrong and Smith, 1992).

A previous study suggested that individual lobes of Parmelia conspersa (Ehrh. ex Ach.) Ach. exhibited a fluctuating pattern of RG over successive months with alternating periods of faster and slower growth (Armstrong and Smith, 1992). Several factors may potentially influence the pattern of monthly growth fluctuation. First, growth fluctuations could be determined by climate, total rainfall and average shortwave radiation appearing to be the most important climatic variables that influence seasonal growth of foliose thalli (Armstrong, 1973, 1993b; Stone, 1986; Boucher and Nash, 1990). Second, when an individual lobe reaches a certain size it divides into two or more lobes (Hale, 1970; Hill, 1992; Armstrong, 1995; Armstrong and Smith, 1999). The process of lobe division may occur over a period of several months (Hill, 1992) and could be associated with changes in RG (Armstrong, 1995). Third, many lobes appear to exhibit periods of very low or apparently zero growth, occasionally over several successive months, even though growth conditions appear to be favourable (Rydzak, 1961; Phillips, 1969; Armstrong, 1991).

The objectives of the present study were: 1) to establish the patterns of monthly fluctuation in RG in a large sample of lobes of the lichen $P$. conspersa over a period of 22 months, 2) to determine the extent to which these fluctuations were correlated with climate, 3 ) to examine the 
frequency and duration of the periods of zero RG, and 4) to determine whether the cycle of lobe division influenced monthly fluctuations in RG.

\section{Materials and Methods}

\section{Site and lichens}

The study was carried out in south Gwynedd, Wales, UK at a site (National Grid Ref SN 6196) described previously (Armstrong, 1974). Approximately circular thalli of $P$. conspersa without fragmenting centres (Armstrong and Smith, 1997) were removed from various south-facing rock surfaces at the site and placed on horizontal boards in an unshaded site in the field, where they remained for at least a year before commencing the growth study.

\section{Radial growth $(R G)$ of lobes}

A sample of 120 lobes was selected from 35 thalli of $P$. conspersa drawn at random from the population on the boards. Between four and eight lobes were chosen from each thallus depending on thallus size. Each of the selected lobes was healthy with at least one active apical growing point. Lobes whose tips had lagged behind their neighbours were not selected. In addition, the lobes were clearly separated from their immediate neighbours for at least $4 \mathrm{~mm}$ of their length as measured from the tip (Armstrong, 1996). RG measurements were made each month for 22 months from September 1996 to June 1998 using previously described methods (Armstrong, 1973, 1975). Essentially, the advance of the lobe tip was measured in relation to fixed markers on the substratum using a binocular microscope fitted with a micrometer scale. Using this method, measurements of RG can be made in a single month to less than $0.1 \mathrm{~mm}$ (Armstrong, 1973, 1975).

\section{Climatic variables}

Climatic data were obtained from the Institute of Grassland and Environmental Research, Plas Gogerddan, near Aberystwyth, approximately eight miles to the south and at the same altitude as the sample site. Previous studies have suggested that a number of climatic variables could influence monthly fluctuations in growth (Armstrong, 1973, 1993). Hence, the following variables were included in the study: 1) total rainfall per month (Armstrong, 1973, Armstrong, 1976, Fisher and Proctor, 1978, Lawrey and Hale, 1977), 2) the total number of rain days per month (Armstrong, 1976), 3) maximum (Tmax) and minimum (Tmin) temperature recorded on each day and averaged for each monthly period (Fisher and Proctor, 1978; Lawrey and Hale, 1977), 4) mean air temperature per month, 5) the total number of air and ground frosts per month, 6) average shortwave radiation (cal cm${ }^{-2}$ ) (Armstrong, 1973; Lawrey and Hale, 1977), and 7) average daily wind speed per month ( $\left.\mathrm{km} \mathrm{hr}^{-1}\right)$ (Armstrong, 1975). The frequency of cloudy days (Hausmann, 1948; Rydzak, 1961; Lawrey and Hale, 1977) and relative humidity may also be usefully measured but these data were not available for the period under study. A limitation of this type of study is that RG at the site is related to climatic records compiled from some distance away (Armstrong, 1991; Lawrey and Hale, 1977) and such data should not be used without corroborating measurements (Lawrey and Hale, 1977). Hence, total rainfall and temperature measurements were also made adjacent to the lichens on a sample of days and these data correlated well with daily records from Plas Gogerddan (Pearson's 'r' >0.80).

\section{Data analysis}

The data for each lobe comprise a 'time series' of 22 consecutive measurements of RG. To detect patterns of fluctuation in growth over this time period, the data were analysed using an autocorrelation method (Priestley, 1982; Armstrong and Smith, 1999; Armstrong, 2000). Autocorrelation detects the strength of a relationship between observations in a time series as a function of the degree of separation between them (Priestley, 1982). The method is based on the principle that if there is a fluctuating pattern of growth over 22 months, RG in adjacent months will be high during a growth peak or low during a lull in growth. In such a case, adjacent pairs of RG measurements taken from all 22 months (comprising the $\mathrm{X}$ and $\mathrm{Y}$ variables) will be positively correlated as measured by the linear regression coefficient (b). If the spacing between the months is increased, i.e., $\mathrm{X}$ and $\mathrm{Y}$ values are separated first by one month, and then by two months, three months etc., it becomes increasingly probable that there will be pairs of values such that one member of the pair will represent a growth peak and the other a lull in growth. Hence, ' $b$ ' will decrease as the degree of separation between the months increases. The degree of separation between months at which the maximum significant negative regression coefficient $\left(-b_{\max }\right)$ occurs is an estimate of the mean duration of the growth peaks over 22 months. In addition, if the growth peaks are distributed in a cyclic pattern, a significant $+b_{\max }$ indicates the peak-to-peak distance. This is because at greater degrees of separation, the months are now so widely spaced that the $\mathrm{X}$ and $\mathrm{Y}$ values span adjacent growth peaks. Hence, ' $b$ ' was calculated for pairs of months and then for months separated by 1, 2, 3, 4, 5, ....., $\mathrm{n}$ months and plotted as a function of the degree of separation between the months. The standard errors of ' $b$ ' are often underestimated and the values of Student's ' $t$ ', used to test the statistical significance of ' $b$ ', overestimated by this method. Therefore, the significance of ' $b$ ' was tested 
Table 1. Distribution of the patterns of monthly variation (September 1996 - June 1998) $(\mathrm{A}=$ Random, $\mathrm{B}=$ Cyclic, $\mathrm{C}=$ Fluctuating, interrupted with periods of zero growth) in radial growth (RG) exhibited by 120 lobes of the foliose lichen Parmelia conspersa over a 22 month period.

\begin{tabular}{lllrr}
\hline & & \multicolumn{4}{c}{ Pattern of growth fluctuation } \\
Diameter & $\mathrm{N}$ & A & B & C \\
\hline $1.0-2.9 \mathrm{~cm}$ & 44 & 30 & 9 & 5 \\
$3.0-8.5 \mathrm{~cm}$ & 76 & 39 & 19 & 18 \\
\hline
\end{tabular}

$\mathrm{N}=$ Number of lobes. Chi-square $\left(\chi^{2}\right)(3 \times 2$ contingency table $)$ : $\chi^{2}=3.83(2 \mathrm{DF}, \mathrm{P}>0.05)$.

Table 2. Number of lobes of the foliose lichen Parmelia conspersa over a 22 month period exhibiting a significant correlation (Pearson's ' $r$ ', $\mathrm{P}<0.05)$ between radial growth $(\mathrm{RG})$ and climatic variables $(\mathrm{R}=$ total rainfall per month, $\mathrm{RD}=$ Number of rain days per month, Tmin $=$ Mean minimum temperature, Tmax $=$ Mean maximum temperature, $\mathrm{AT}=$ Mean air temperature, $\mathrm{SWR}=$ mean daily shortwave radiation, $\mathrm{AF}=$ Frequency of air frosts per month, $\mathrm{GF}=$ Frequency of ground frosts per month, WS $=$ Average daily wind speed, $\mathrm{NS}=$ Lobes exhibiting no significant correlation with climatic variables).

\begin{tabular}{llllllllll}
\multicolumn{3}{c}{ Climatic variable } & & & & & & & \\
$\mathrm{R}$ & $\mathrm{RD}$ & $\mathrm{Tmin}$ & $\mathrm{Tmax}$ & $\mathrm{AT}$ & $\mathrm{SWR}$ & $\mathrm{AF}$ & GF & WS & NS \\
\hline 12 & 11 & 6 & 4 & 6 & 3 & 4 & 6 & 3 & 83 \\
\hline
\end{tabular}

Total number of lobes examined $=120$.

Table 3. The number of periods of zero growth coinciding with each month of the year totaled over all 22 months.

\begin{tabular}{lrll}
\hline January & 106 & July & 58 \\
February & 82 & August & 68 \\
March & 77 & September & 39 \\
April & 100 & October & 31 \\
May & 90 & November & 18 \\
June & 65 & December & 60
\end{tabular}

$\chi^{2}$ goodness of fit test $=122.01(\mathrm{P}<0.001)$.

by the Breusch-Godfrey test (Priestley, 1982). Based on these analyses, each lobe was classified as having one of three types of fluctuation, viz., 1) a random pattern of growth fluctuations over 22 months (no significant values of ' $b$ '), 2) a cyclic pattern of growth in which high RG in a particular month or months was immediately followed by low or zero growth (significant $-b_{\max }$ and $+b_{\max }$ ), and 3 ) a period of high or fluctuating growth interrupted by one or more longer periods of zero growth (significant $-b_{\max }$ and non significant $+b_{\max }$ ).

Correlations between the monthly growth of each lobe and climatic variables were tested using Pearson's correlation coefficient (' $r$ '). To determine whether lobes significantly correlated with climate were associated with a specific type of growth fluctuation was tested using a $\chi^{2}$ contingency table. To determine whether there was a relationship between the type of growth fluctuation and thallus size, lobes were classified into two size classes, viz., $1-2.9 \mathrm{~cm}$ and $3.0-8.5 \mathrm{~cm}$ in diameter, and the proportions of the different types of fluctuation compared between sizes using a $\chi^{2}$ contingency table.

The majority of lobes exhibited periods of 1 month or more in which RG was not detectable using the present method. To determine whether these periods of 'zero growth' were distributed as a random variable, the frequency distribution of periods of zero growth of $0,1,2$, $3, \ldots \mathrm{n}$, months duration in the population of lobes as a whole was compared with the Poisson distribution. Goodness of fit of the data to the Poisson distribution was tested using chi-square $\left(\chi^{2}\right)$ and Kolmogorov-Smirnov (KS) tests. In addition, the frequency of periods of zero growth in different months of the year was compared using a $\chi^{2}$ goodness of fit test.

\section{$R G$ and division of the lobe}

To determine whether there was a relationship between RG and the stage of division of the lobe, six thalli of $P$. conspersa were selected at random from the boards. From each thallus, 5-6 lobes were randomly chosen. Lobes were at different stages of division as indicated by the bifurcation of the tips. The degree of bifurcation of the lobe tip of each lobe was measured on 1, June 2000 from the furthest extending growth point at the tip of the lobe to the point of maximum bifurcation using Vernier calipers (Armstrong, 1995). The RG of each lobe was then measured over a subsequent two-month period using previously described methods (Armstrong, 1973). The relationship between degree of division of the lobe at the start of the experiment and subsequent RG was studied using correlation and regression methods.

\section{Results}

Examples of the three main types of monthly fluctuation in RG are shown in Figs. 1 to 3. In Fig. 1, growth fluctuations were essentially random (no significant values of ' $b$ ') over 22 successive months without a distinct pattern, i.e., there were periods of low RG, a period of zero RG, and a period of fluctuating RG. In Fig. 2, there was a cyclic pattern of RG (significant $-b_{\max }$ and $+b_{\max }$ ), significant growth in a single or group of consecutive months being followed by low growth. In Fig. 3, there was a period of high though fluctuating growth over the first 14 months followed by a period of zero growth of eight months (significant $-b_{\max }$ and non-significant $+b_{\max }$ ). Fig. 4 shows 


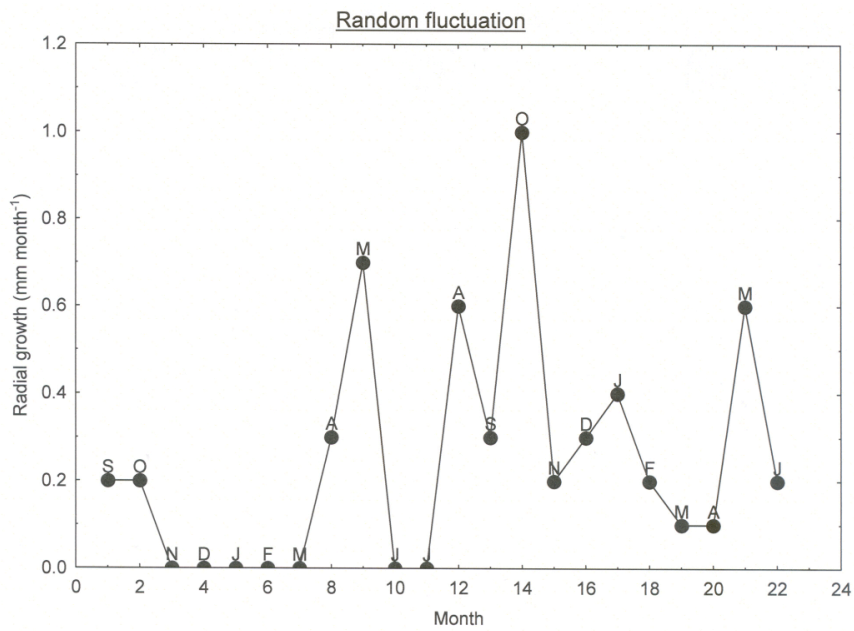

Figure 1. Growth of a single lobe of the foliose lichen Parmelia conspersa showing a random pattern of radial growth over 22 months. Point labels indicate months of the year in sequence from September 1996 to June 1998.

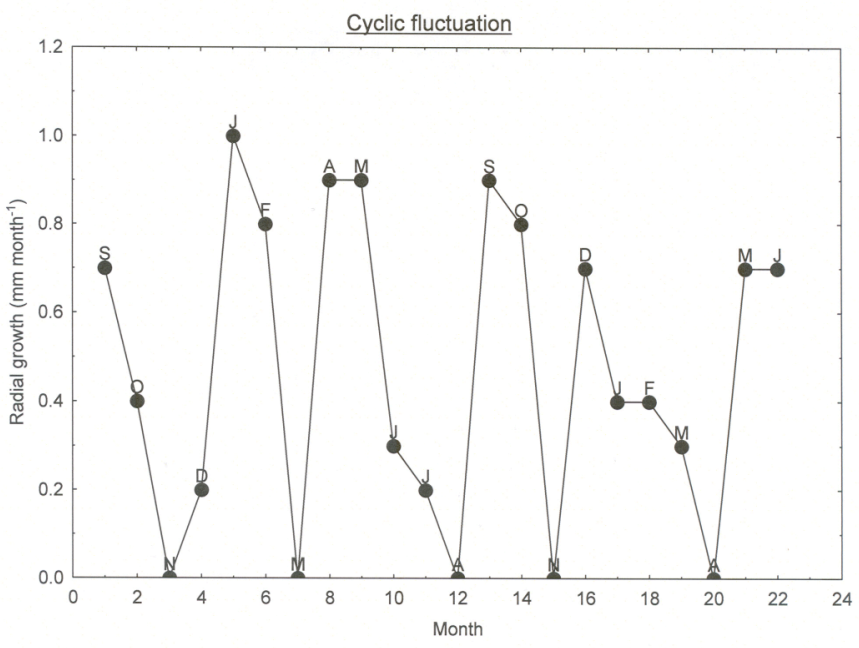

Figure 2. Growth of a single lobe of the foliose lichen Parmelia conspersa showing a cyclic pattern of radial growth over 22 months. Point labels indicate months of the year in sequence from September 1996 to June 1998.

the autocorrelation analysis corresponding to the lobe in Fig. 2. The regression coefficient (b) reaches a significant negative peak $\left(-b_{\max }\right)$ at a separation of 2 months and a significant positive peak $\left(+\mathrm{b}_{\max }\right)$ at 4 months suggesting peaks of $\mathrm{RG}$ of two months duration repeating with an mean peak to peak distance of 4 months.

The frequency of the three types of monthly fluctuation exhibited by all 120 lobes is summarised in Table 1 . In the data as a whole, monthly variations in RG were random in $69 / 120(58 \%)$ of lobes, showed a cyclic pattern of growth in $28 / 120(23 \%)$ of lobes, while a period of fluctuating growth interrupted by a longer period of zero growth was present in

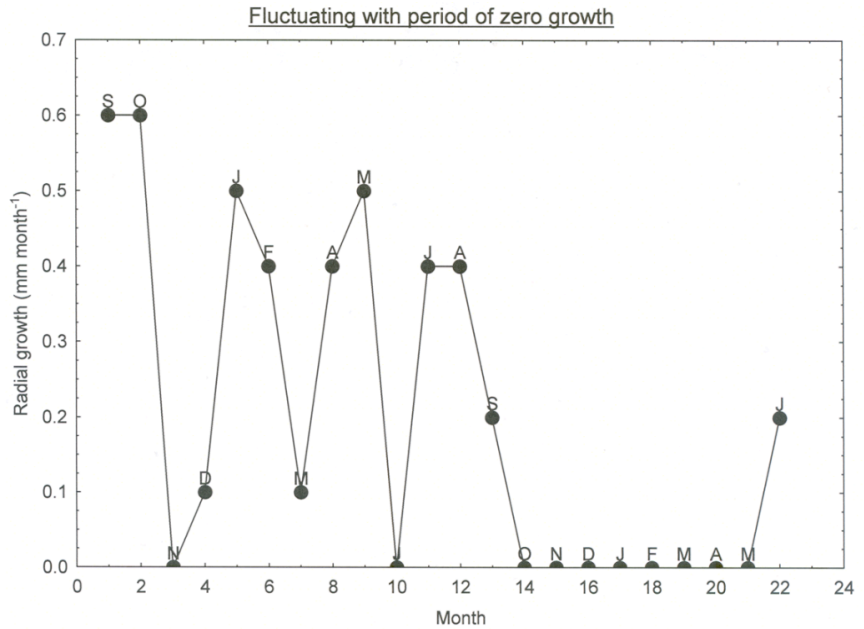

Figure 3. Growth of a single lobe of the foliose lichen Parmelia conspersa showing a fluctuating pattern of radial growth over 22 months but interrupted by a period of eight months of zero growth. Point labels indicate months of the year in sequence from September 1996 to June 1998.

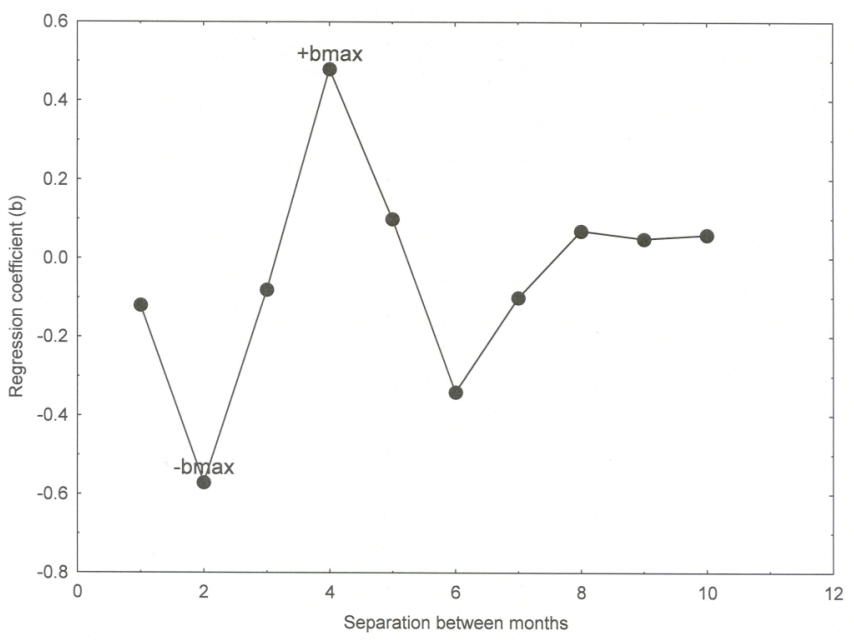

Figure 4. Auto correlation analysis of the lobe shown in Fig. 2, $-b_{\max }$ indicates the average length of the growth peaks in months and $+b_{\max }$ the peak to peak distance. The $\mathrm{X}$ axis represents the degree of separation between months at whish the regression coefficient ' $b$ ' was calculated.

$23 / 120(19 \%)$ lobes. In $28 / 35(80 \%)$ of thalli, two or all three patterns of fluctuation were present within the same thallus. In thalli exhibiting a cyclic pattern of growth, the mean duration of the growth periods was 3 months ( $\mathrm{SE}=$ $0.39)$ with an average peak to peak distance of 6.5 months $(\mathrm{SE}=0.52)$. There was no significant association between the pattern of lobe growth and the size class of the thallus $\left(\chi^{2}=3.83, \mathrm{P}>0.05\right)$.

The frequency of significant correlations between RG and the climatic factors is shown in Table 2. Of the lobes examined, 83/120 (69\%) did not show any significant correlations with climate. Of the $37 / 120(31 \%)$ lobes that 


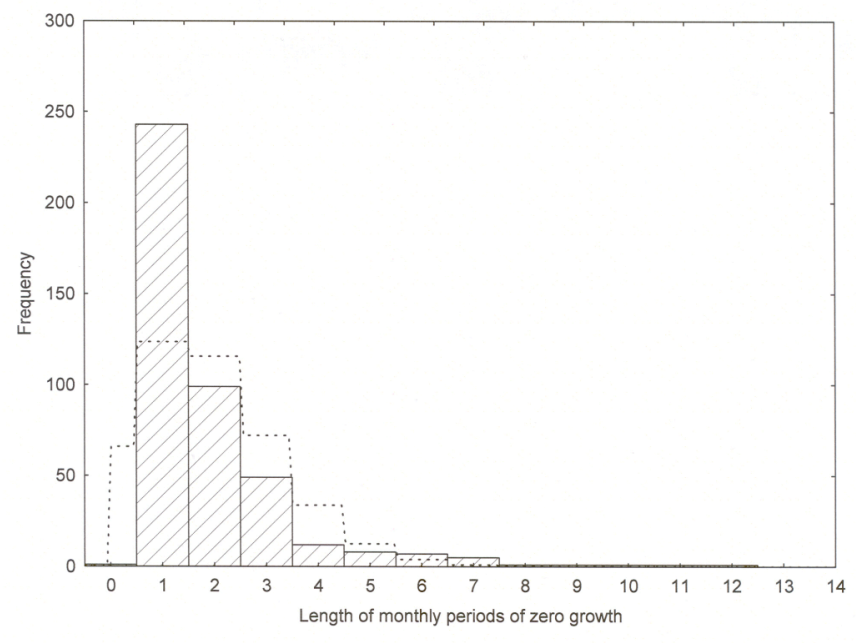

Figure 5. Frequency distribution of the length of periods in months in which zero growth occurred in a population of 120 lobes measured over 22 months of the lichen Parmelia conspersa. The dashed histogram indicates the frequencies that would be expected from a Poisson distribution (Goodness of fit to Poisson $\chi^{2}=230.8$, $\mathrm{P}<0.001 ; \mathrm{KS}=0.15, \mathrm{P}<0.01)$

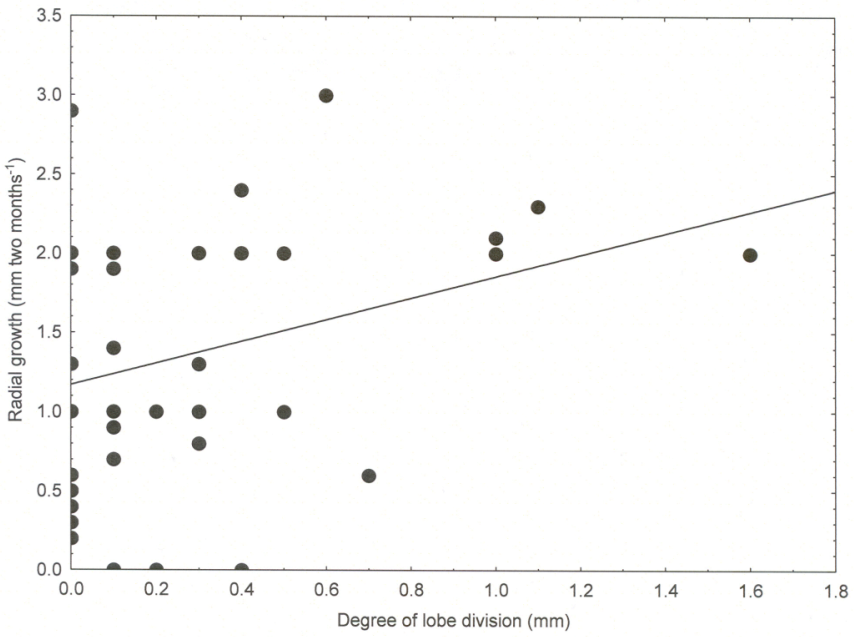

Figure 6. Relationship between the degree of division of the lobe (extent of bifurcation of the tip) and radial growth (RG) of the lobe in a sample of lobes of Parmelia conspersa $\left(r^{2}=0.096\right)$.

were significantly correlated, most correlations were either with total rainfall or the number of rain days per month. Several of the lobes exhibited multiple correlations with two or more climatic variables. There was no significant relationship between the type of growth fluctuation and whether the lobe was or was not significantly correlated with climate $\left(\chi^{2}=2.84, \mathrm{P}>0.05\right)$.

The frequency distribution of the monthly periods of zero RG is shown in Fig. 5. Periods of zero growth of at least one month duration occurred in all but one of the lobes studied, were common up to three successive months, and were present up to a maximum of 12 months in a small number of lobes. This distribution deviated significantly from a Poisson distribution $\left(\chi^{2}=230.8, \mathrm{P}<0.001\right.$; KS $=$ $0.15, \mathrm{P}<0.01)$ suggesting that the periods of zero growth were not randomly distributed. Hence, lobes exhibiting no periods of zero growth were much rarer than predicted by the Poisson distribution. In addition, the frequency of periods of zero growth in a single month and greater than about 6 months duration were more common than expected. The distribution of periods of zero growth throughout the year is shown in Table 3. Periods of zero RG were not evenly distributed through the year, the $\chi^{2}$ goodness of fit test $\left(\chi^{2}=122.01, \mathrm{P}<0.001\right)$ suggesting that such periods were most common in January and April and least frequent in September to November.

The relationship between the degree of initial lobe division and subsequent $R G$ in a two-month period is shown in Fig. 6. In the sample of lobes as a whole, RG over two months was positively correlated with the degree of division of the lobe $(r=0.31, P<0.05)$, more deeply divided lobes having higher growth rates. Nevertheless the value of the coefficient of determination $\left(\mathrm{r}^{2}\right)$ suggested that only $9.6 \%$ of the variance in $\mathrm{RG}$ could be attributable to the degree of lobe bifurcation.

\section{Discussion}

The first objective was to establish the patterns of monthly growth fluctuation of $P$. conspersa lobes over 22 months. Periods of fluctuating RG were a characteristic feature of all lobes studied. The autocorrelation analysis identified three main patterns, viz., random fluctuations, a cyclic pattern, and a fluctuating pattern of RG interrupted by periods of zero growth, random growth being the most common. Few previous studies have systematically examined temporal growth fluctuations in foliose lichens. Phillips (1969) measured the growth of Menegazzia terebrata and Lobaria pulmonaria in successive years and found that rapid RG of a lobe was usually followed or preceded by slower growth. In addition, some lobes grew at two to three times the average and others not at all.

The second objective was to determine whether growth fluctuations could be explained by climate. In previous studies of foliose species (Armstrong, 1973, 1993b, 2006; Armstrong and Smith, 1992), seasonal variations in RG of whole thalli have been correlated with climatic variables, most usually with total rainfall or shortwave radiation. In the present study, less than a third of lobes were significantly correlated with climate, most commonly with either total monthly rainfall, or number of rain days per month. Lack of correlation could be due to RG being associated with variables not measured, to a more complex combination of climatic variables (Armstrong, 1993b, 2006), to a lag phase between climatic events and RG 
(Armstrong, 2006), or to non-linear growth responses (Armstrong, 2006). Whether or not RG of a lobe was correlated with climate was not related to the pattern of growth. Hence, climatic variations were not responsible for any specific type of growth fluctuation in $P$. conspersa.

The third objective was to study the duration and distribution of periods of very low or zero growth. There are several possible explanations for such periods. First, in Poland, lichen growth practically ceases during the winter months with best growth in cool wet summers (Rydzak, 1961). In the present study, periods of zero growth were most frequent in the period January to May and least frequent in the autumn. Low temperatures could explain low growth in January but are unlikely to explain the high frequency of such periods in April and May. Second, lobes may become narrower as they grow in length (Hill, 1992) and $\mathrm{RG}$ may cease when the lobe is not wide enough to provide sufficient carbohydrate for RG (Armstrong, 1991, 1993a; Hill, 1992; Armstrong and Smith, 1998). There was no evidence, however, that lobe width changed consistently over 22 months. Third, periods of zero growth could reflect changes in the pattern of allocation of carbohydrates within the lobe since individual lobes show considerable variation in the levels of ribitol, arabitol, and mannitol (Armstrong and Smith, 1994).

The fourth objective was to determine whether growth fluctuations were correlated with lobe division. The pattern of lobe division is irregular and complex (Hale, 1970), each major lobe producing new lobes from two or more apical and marginal bulges (Hale, 1970). However, lack of space at the margin often results in the atrophy of many potential lobes. To date, it has not been possible to accurately follow the process of lobe division and the fate of subsequent lobes longitudinally as it would require virtually continuous observation in the field (Armstrong and Smith, 1992). However, examination of lobes at the margin suggests that lobe division does proceed in a cyclic pattern with regularly repeating events of growth and division (Hill, 1992). In Parmelia saxatilis, for example, Hill (1992) reported an average of three to five divisions a year while in $P$. conspersa, the average number of new lobes increased linearly over 4.5 years resulting in the average production of one new lobe every four to five months (Armstrong, 1992). In addition, a positive correlation was observed between the initial degree of division of the lobe and $R G$ over a succeeding two months interval. Hence, $R G$ of a lobe may fluctuate to some extent according to the stage of division of the lobe and therefore, could be one factor responsible for the cyclic pattern of $R G$ in some lobes. Nevertheless, the degree of division of the lobe accounts for only approximately $10 \%$ of the variance in $\mathrm{RG}$ suggesting there are other factors contributing to a cyclic pattern. In addition, fluctuations in RG associated with lobe division are much less than many of the monthly variations in P. conspersa.
Lobes exhibiting different patterns of growth fluctuation coexist within the same thallus e.g., in 10/35 thalli, different lobes exhibited all three patterns of growth variation. Hence, the local microenvironment of a lobe within the thallus also influences growth fluctuation. For example, RG of lobes that extend beyond the margin may decline as they enter a more unfavourable microclimate (Armstrong, 1993a). By contrast, lobes more tightly crowded together may retain moisture for longer periods, and exhibit a more sustained period of RG (Armstrong, 1976).

In conclusion, all 120 lobes of $P$. conspersa exhibited periods of fluctuating RG with three distinct patterns over 22 months: a random pattern of growth, cyclic growth, and fluctuating growth interrupted by periods of zero growth, random $\mathrm{RG}$ being the most common. The data suggest the hypothesis that lobes of $P$. conspersa exhibit a pattern of cyclic RG determined, in part, by lobe division. The combined effects of climate, periods of zero growth, and microvariations in the environment of a lobe within a thallus are superimposed on this cyclic pattern and may be responsible for the random patterns exhibited by many of the lobes. A previous paper (Armstrong and Smith, 1992) speculated on how a colony of apparently independently growing lobes could maintain a degree of thallus symmetry. The presence of a significant proportion of lobes growing over time in an essentially random manner could help to maintain thallus symmetry as the effects of periods of very low and high growth would average out over the thallus as a whole.

\section{REFERENCES}

Aplin, P.S. and Hill, D.J. 1979. Growth analysis of circular lichen thalli. Journal of Theoretical Biology 78: 347-363.

Armstrong, R.A. 1973. Seasonal growth and growth rate colony size relationships in six species of saxicolous lichens. New Phytologist 72: 1023-1030.

Armstrong, R.A. 1974. The descriptive ecology of saxicolous lichens in an area of South Merionethshire, Wales. Journal of Ecology 62: 33-45.

Armstrong, R.A. 1975. The influence of aspect on the pattern of seasonal growth in the lichen Parmelia glabratula ssp. fuliginosa. New Phytologist 75: 245-251.

Armstrong, R.A. 1976. The influence of the frequency of wetting and drying on the radial growth of three saxicolous lichens in the field. New Phytologist 77: 719-724.

Armstrong, R.A. 1991. Experimental studies of lobe growth in the lichen Parmelia conspersa (Ehrh. ex, Ach.) Ach. New Phytologist 119: 315-319.

Armstrong, R.A. 1993a. Factors determining lobe growth in foliose lichen thalli. New Phytologist 124: 675-679.

Armstrong, R.A. 1993b. Seasonal growth of foliose lichens in successive years in south Gwynedd, Wales. Environmental and Experimental Botany 33: 225-232.

Armstrong, R.A. 1995. Lobe interactions within the thallus margin and the maintenance of symmetry in the lichen Parmelia conspersa (Ehrh. ex Ach.) Ach. Symbiosis 18: 129-142. 
Armstrong, R.A. 1996. Factors determining the growth curve of the foliose lichen Parmelia conspersa. New Phytologist 134: 517-522.

Armstrong, R.A. 2000. Analysis of spatial patterns in histological sections of brain tissue using a method based on regression. Journal of Neuroscience Methods 95: 39-45.

Armstrong, R.A. 2003. Lobe connections and lobe crowding are associated with growth rate in the lichen Xanthoparmelia conspersa. Symbiosis 34: 133-143.

Armstrong, R.A. 2006. Seasonal growth of the crustose lichen Rhizocarpon geographicum (L.) DC. in south Gwynedd, Wales. Symbiosis 41: 97-102.

Armstrong, R.A. and Smith, S.N. 1992. Lobe growth variation and the maintenance of symmetry in foliose lichen thalli. Symbiosis 12: $145-158$.

Armstrong, R.A. and Smith, S.N. 1994. The levels of ribitol, arabitol, and mannitol in individual lobes of the lichen Parmelia conspersa (Ehrh. Ex Ach.) Ach. Environmental and Experimental Botany 34: 253-260.

Armstrong, R.A. and Smith, S.N. 1997. Factors associated with degeneration of the thallus centre in foliose lichens. Symbiosis 22: 293-302.

Armstrong, R.A. and Smith, S.N. 1998. Does radial growth of the lichen Parmelia conspersa depend exclusively on growth processes at the lobe tip? Environmental and Experimental Botany 39: 263-269.

Armstrong, R.A. and Smith, S.N. 1999. Factors associated with lobe division in the lichen Parmelia conspersa (Ehrh. ex. Ach.) Ach. Symbiosis 26: 265-277.

Benedict, J.B. and Nash, T.H. 1990. Radial growth and habitat selection by morphologically similar chemotypes of Xanthoparmelia. Bryologist 93: 319-327.

Benedict, J.B. 1991. Experiments on lichen growth. I. Seasonal patterns and environmental control. Arctic and Alpine Research 22: 244-254.

Boucher, V.L. and Nash, T.H. III. 1990. Growth patterns in Ramalina menziesii in California: coastal versus inland populations. Bryologist 93: 295-302.
Fisher, P.J. and Proctor, M.C.F. 1978. Observations on a season's growth of Parmelia caperata and P. sulcata in South Devon. Lichenologist 10: 81-89.

Hale, M.E. 1970. Single-lobe growth rate patterns in the lichen Parmelia caperata. Bryologist 73: 72-81.

Hale, M.E. 1973. Growth. In: The Lichens. Ahmadjian, V. and M.E. Hale, M.E., eds. Academic Press, London and New York, pp. 473-492.

Hausmann, E.H. 1948. Measurements of the annual growth rate of two species of rock lichen. Bulletin of the Torrey Botanical Club 75: $116-117$.

Hill, D.J. 1984. Studies on the growth of lichens. 1. Lobe formation and the maintenance of circularity in crustose species. Lichenologist 16: 265-287.

Hill, D.J. 1992. Lobe growth in lichen thalli. Symbiosis 14: 325333.

Hooker, D.J. 1980. Lobe growth and marginal zonation in crustose lichens. Lichenologist 12: 313-323.

Lawrey, J.D. and Hale, M.E. 1977. Studies on lichen growth rates at Plummers Island, Maryland. Proceedings of the Biological Society of Washington 90: 698-725.

Phillips, H.C. 1969. Annual growth rates of three species of foliose lichens determined photographically. Bulletin of the Torrey Botanical Club 96: 202-206.

Priestley, M.B. 1982. Spectral Analysis and Time Series. Academic Press, London and New York.

Rydzak, J. 1961. Investigations on the growth rate of lichens. Annales Universitatis Mariae Curie-Sklodowska (Lublin, Poland), sec. C, 16: 1-15.

Snedecor, G.W. and Cochran, W.G. 1980. Statistical Methods, 7th edn. Iowa State University Press, Iowa.

Stone, D.F. 1986. Succession of epiphytes on Quercus garryana branches in the Willamette Valley of western Oregon. Ph.D. Thesis, University of Oregon, Eugene, OR. 
R.A. ARMSTRONG 